\title{
Incretin Therapy and Heart Failure
}

\author{
Jun-ichi Oyama, MD, PhD; Koichi Node, MD, PhD
}

Type 2 diabetes mellitus (T2DM) is widely prevalent and a critical risk factor for cardiovascular disease that increases both morbidity and mortality. Recently, new therapies based on the actions of the incretin hormones have become widely used, offering advantages over conventional treatments by limiting hypoglycemia and achieving glycemic control. Moreover, many experimental studies have suggested that GLP-1 and related drugs exert cardioprotective effects on atherosclerosis and cardiac dysfunction both in vitro and in vivo. However, there is thus far little clinical evidence supporting the efficacy of incretin therapy in patients with cardiovascular disease. This review focuses on the effects of GLP-1-related therapy on cardiac function from the bench to the bed, with a discussion of possible underlying mechanisms. (Circ $J$ 2014; 78: 819-824)

Key Words: DPP-4 inhibitor; GLP-1; Heart failure; Incretin; Type 2 diabetes mellitus (T2DM)

$\mathbf{T}$ ype 2 diabetes (T2DM) is one of the most important risk factors for the development of cardiovascular disease, as it promotes both systemic atherosclerosis and lifestyle-associated diseases. Incretin-based therapies, including treatment with glucagon-like peptide-1 (GLP-1) receptor (GLP-1R) agonists and dipeptidyl peptidase (DPP)-4 inhibitors, have become widely used as a new class of antidiabetic drugs that exhibit different mechanisms of action from those of conventional antidiabetic agents. Incretin hormones depend on blood glucose to stimulate insulin. Because the use of DPP-4 inhibitors is associated with a lower incidence of hypoglycemia than is observed with conventional hypoglycemic drugs, they potentially improve the mortality rate of patients with T2DM by achieving strict glycemic control without causing fatal hypoglycemia. The GLP-1R has been detected in coronary endothelial cells, coronary smooth muscle cells, cardiomyocytes and human umbilical vein endothelial cells, as well as monocytes and macrophages. ${ }^{1-4}$ Interestingly, GLP-1 acts on multiple organs, not simply the pancreas, including the heart and vasculature (Figure 1). Therefore, GLP-1-related therapy exerts effects on the cardiovascular system, and recent evidence suggests that GLP-1-related treatment has potent pleiotropic beneficial effects on cardiovascular risk factors, beyond its effects on glycemic control. This review focuses on the theoretical and practical effects of incretin-related therapy on cardiac function, with a description of possible mechanism(s) of action.

\section{Biology of Incretins}

Incretin hormones are secreted from the gastrointestinal tract in response to food intake and have several systemic effects, including glucose-dependent stimulation of insulin secretion by pancreatic beta cells. Two incretins have been identified: GLP-1, which is derived from the $L$ cells of the distal small intestine and large bowel, and glucose-dependent insulinotropic polypeptide (GIP), which is derived from the K cells of the proximal small intestine. GLP-1 and GIP are glucose-lowering agents that can interfere with postprandial hyperglycemia, which has been demonstrated as associated with cardiovascular complications. The biologically active forms of GLP-1 include GLP-1(7-37) and GLP-1(7-36)amide. These peptides arise from the selective cleavage of the proglucagon molecule. GLP-1(7-36)amide is abundant in the circulation after meals and stimulates insulin secretion by interacting with the GLP-1 receptors on pancreatic beta cells. DPP-4 degrades GLP-1(7-36)amide to inactive GLP-1(9-36)amide, and DPP-4 inhibitors bind to DPP-4 to prevent the breakdown of GLP- 1 and GIP, ${ }^{5}$ thereby increasing the half-life and bioavailability of active incretins, ultimately enhancing their physiological effects. GLP-1(7-36)amide has been widely studied for its role as an active incretin and is referred to as GLP-1, unless otherwise specified. GLP-1(9-36) amide is thought to be an inactive metabolite because of its 1,000-fold lower affinity for GLP-1R and action as a weak competitive antagonist without incretin activity at pharmacological doses. However, GLP-1(9-36)amide may have potent effects on the cardiovascular system, similar to GLP-1(7-36) amide. Although it remains controversial, GLP-1 may undergo multiple cycles of enzymatic degradation by DPP-4 and neprilysin. Therefore, the precise biological pathways of GLP-1 and related enzymes and the roles of metabolites in each step of the process in vivo need to be elucidated in the near future.

\section{Effects of Incretins on Cardiac Function}

\section{Cardiomyocytes in Vitro}

GLP-1 rapidly increases the 3'-5' -cyclic adenosine monophosphate (cAMP) levels in adult rat ventricular cardiac myocytes, consistent with its effect on pancreatic beta cells, in a manner

Received December 24, 2013; revised manuscript received February 3, 2014; accepted February 5, 2014; released online March 7, 2014

Departments of Advanced Cardiology (J.O.), Cardiovascular Medicine (K.N.), Saga University Faculty of Medicine, Saga, Japan

Mailing address: Jun-ichi Oyama, Department of Advanced Cardiology, Saga University, 5-1-1 Nabeshima, Saga 849-8501, Japan. Email: junoyama@cc.saga -u.ac.jp

ISSN-1346-9843 doi:10.1253/circj.CJ-13-1561

All rights are reserved to the Japanese Circulation Society. For permissions, please e-mail: cj@j-circ.or.jp 


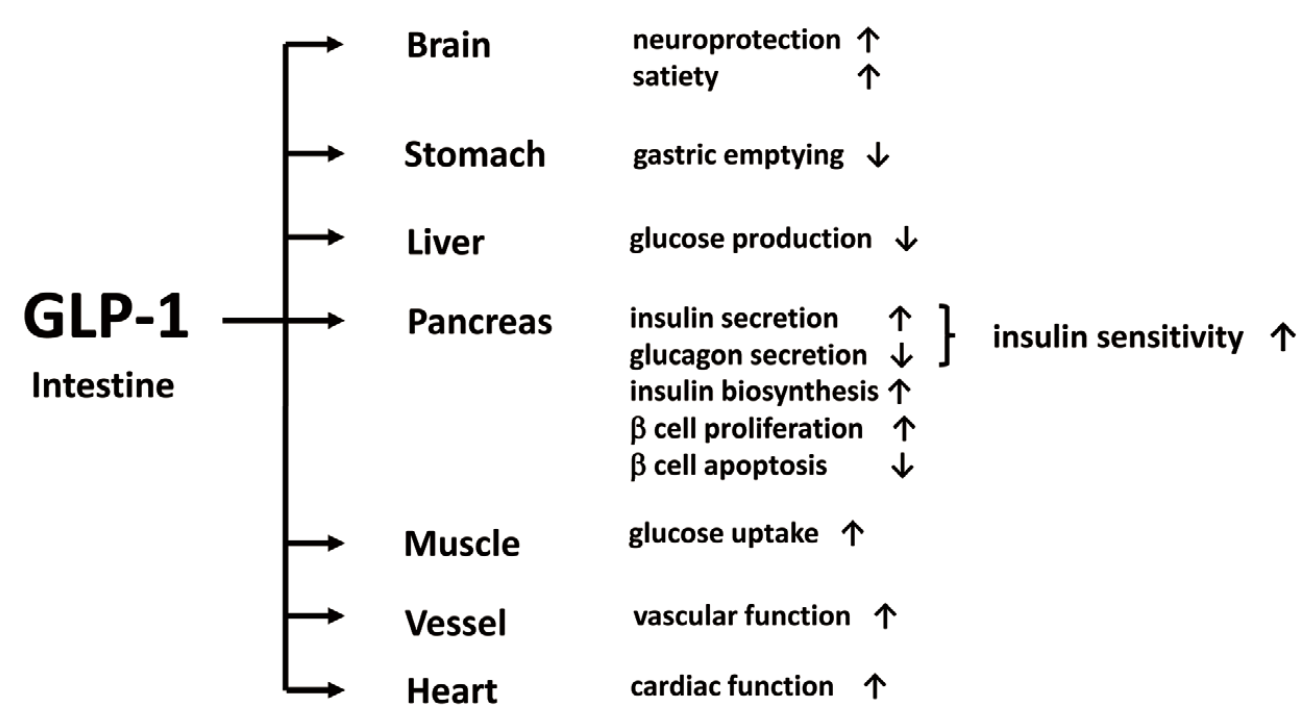

Figure 1. Schema of the physiological effects of glucagon-like peptide-1 (GLP-1) on various organs.

that is not coupled with an increase in the intracellular $\mathrm{Ca}^{2+}$ concentration or subsequent cardiomyocyte contractility, as would be expected for cAMP-generating agents in the heart. ${ }^{6}$ Liraglutide increases cAMP formation and reduces caspase-3 activation in murine cardiomyocytes in a GLP-1R-dependent manner in vitro. ${ }^{7}$ Therefore, GLP-1R activation in primary cultures of cardiomyocytes increases the cAMP content in association with anti-apoptotic properties.

\section{In Vivo and ex Vivo Experimental Data}

GLP-1R knockout mice exhibit a reduced resting heart rate (HR), elevated left ventricular end-diastolic pressure (LVEDP) and increased LV thickness because of impaired LV contractility and diastolic dysfunction, as compared with wild-type mice. ${ }^{8}$ Conversely, GLP-1R preserves the HR and LV thickness and normally lowers the LVEDP.

\section{Model of Myocardial Ischemia-Reperfusion (IR) and Infarction (MI)}

GLP-1 and its related therapy have been demonstrated to inhibit the activation of cell death mechanisms in several experimental models of myocardial IR and MI.

GLP-1 has also been demonstrated to exert beneficial effects on cardiac function via downregulation of inflammatory cells activated by MI.,10 In addition, GLP-1 enhances LV function by myocardial glucose uptake in the postischemic myocardium through an increase in the expression of glucose transporter (GLUT)-1 and -4 in the myocardium in association with increased p38 $\alpha$ MAP kinase activity, eNOS expression and myocardial NO uptake, although GLP-1 changes neither the myocardium adenylyl cyclase activity nor the level of Akt phosphorylation, known insulin-dependent signaling pathways for glucose uptake. .,11,12 $^{2}$

GLP-1 and the GLP-1(9-36) metabolite also improve myocardial contractility and coronary blood flow following ischemia in a mouse perfused heart model. ${ }^{4}$ GLP-1 directly protects the heart against myocardial IR injury and reduces the activation of the pro-apoptotic protein, Bad, as well as the infarct size in isolated perfused rat hearts and animal models of IR; these effects are abolished in the hearts in vitro by GLP-1R antagonists, cAMP inhibitors, phosphoinositide 3-kinase (PI3K) inhibitors and p42/44 mitogen-activated protein kinase inhibitors. ${ }^{13}$ DPP-4-resistant GLP-1 analogs fused to non-glycosylated human transferrin possess anti-apoptotic properties accompanied by a reduction in the infarct size and improvements in wall motion abnormalities and the ejection fraction $(E F)$ in a model of myocardial IR in rabbits. ${ }^{14}$ The infusion of GLP-1 or the exenatide analog at 2 weeks after coronary ligation significantly increases the LVEF, while also reducing the incidence of adverse LV remodeling and improving survival. ${ }^{15}$ Exenatide reduces the infarct size and reactive oxygen species (ROS) production and inhibits caspase-3 expression and DNA fragmentation in a porcine model of myocardial IR injury. ${ }^{16} \mathrm{Sim}-$ ilarly, treatment with liraglutide for 1 week prior to coronary ligation in mice reduces both the frequency of cardiac rupture and the infarct size, and increases the cardiac output (CO) and survival rate via the inhibition of caspase- 3 activation in cardiomyocytes. ${ }^{7}$ Furthermore, albiglutide therapy preserves myocardial viability and reduces the production of lactate after IR injury in the rat heart. ${ }^{17}$

The genetic deletion or chemical inhibition of DPP-4 in mice improves their cardiac function after MI by activating cell survival signaling, including that of phosphorylated Akt and pGSK $3 \beta .{ }^{18}$ Combined treatment of mice with granulocyte colony-stimulating factor and a DPP-4 inhibitor preserves cardiac function via enhanced stem cell mobilization and cardiomyocyte regeneration after MI. ${ }^{19}$

In summary, a number of findings suggest that the cardioprotective effects of incretins in IR models are mediated by: (1) reductions in the number of inflammatory cells,,${ }^{9,10}$ (2) improvements in myocardial circulation, ${ }^{10}(3)$ increases in the level of myocardial glucose uptake in order to stimulate more efficient ATP production, , 71,12,17 and (4) activation of reperfusion injury signaling kinase (RISK) pathway kinases, such as PI3K, ERK1/2, cAMP, PKA, Akt and P70S6K, ${ }^{7,18,20-26}$ as PI3K activation results in myocardial protection in the setting of IR injury. ${ }^{27}$ 


\begin{tabular}{|c|c|c|c|}
\hline Author & Pathology & Therapy & Results \\
\hline Nikokaidis et al${ }^{28}$ & $\begin{array}{l}\text { AMI with PCI vs. } \\
\text { healthy subjects }\end{array}$ & GLP-1 & $\mathrm{EF} \uparrow$ \\
\hline Lønborg et al ${ }^{34}$ & AMI with $\mathrm{PCl}$ & Exenatide & $\begin{array}{l}\text { Myocardial salvage } \\
\text { index } \uparrow\end{array}$ \\
\hline Sokos GG et al ${ }^{35}$ & $C A D$ with $C A B G$ & GLP-1 & $\underset{\text { Arrhythmia } \downarrow}{\mathrm{EF} \rightarrow}$ \\
\hline Read et al ${ }^{36}$ & CAD & $\begin{array}{l}\text { Sitagliptin vs. } \\
\text { placebo }\end{array}$ & $\begin{array}{c}\text { Myocardial stunning } \downarrow \\
\qquad F \uparrow\end{array}$ \\
\hline Sokos et $\mathrm{a}^{37}$ & Heart failure & GLP-1 & $\mathrm{EF} \uparrow$ \\
\hline Halbirk et al ${ }^{38}$ & Heart failure & GLP-1 & $\begin{array}{c}\mathrm{HR} \uparrow, \mathrm{DBP} \uparrow \\
\mathrm{EF}, \mathrm{BNP} \rightarrow\end{array}$ \\
\hline Trainsdottir et al ${ }^{39}$ & $\begin{array}{l}\text { T2DM with } \\
\text { heart failure }\end{array}$ & $\begin{array}{l}\text { Recombinant } \\
\text { GLP-1 }\end{array}$ & $\begin{array}{l}\text { Trend in cardiac } \\
\text { function } \uparrow\end{array}$ \\
\hline Gutzwiller et al ${ }^{42}$ & $\begin{array}{l}\text { Obese vs. } \\
\text { healthy subjects }\end{array}$ & GLP-1 & Natriuresis $\uparrow$ \\
\hline
\end{tabular}

AMI, acute myocardial infarction; BNP, B-type natriuretic peptide; CABG, coronary artery bypass graft; CAD, coronary artery disease; DBP, diastolic blood pressure; EF, ejection fraction; GLP-1; glucagon-like peptide-1; HF, heart failure; $\mathrm{PCl}$, percutaneous coronary intervention.

\section{Model of HF}

Studies using animal models have demonstrated that GLP-1R activation-independent actions via the effects of GLP-1R may have a beneficial impact on the failing heart. In dogs with pacing-induced dilated cardiomyopathy (DCM), the infusion of recombinant GLP-1, GLP-1 (7-36) and GLP-1 (9-36) increases the myocardial glucose uptake and insulin sensitivity, improves LV function, stroke volume (SV) and CO, enhances cardiac insulin sensitivity and the LV dP/dt values and decreases the LVEDP, HR and systemic vascular resistance. ${ }^{28,29}$ Moreover, GLP-1 decreases the HR and increases LV systolic function, in addition to reducing the plasma levels of norepinephrine and glucagon. In spontaneously hypertensive and HF-prone rats, GLP-1 treatment for 3 months improves the survival rate and preserves LV contractility in association with reduced cardiomyocyte apoptosis. ${ }^{30}$ The administration of sitagliptin for 3 weeks to nondiabetic pigs with pacing-induced DCM results in a reduced $\mathrm{HR}$, increased $\mathrm{SV}$ and preserved renal function. ${ }^{31}$ However, the administration of vildagliptin to nondiabetic rats before or after coronary ligation has no beneficial effects on either LV function or cardiac gene expression..$^{32}$ Sitagliptin therapy in $\mathrm{db} / \mathrm{db}$ mice reduces AMPK and acetyl CoA carboxylase phosphorylation, as well as CD36 expression in the sarcolemmal membrane of the myocardium, suggesting that DPP-4 inhibition reduces myocardial fatty acid (FA) uptake and subsequent metabolism. ${ }^{33}$ However, treatment with sitagliptin does not improve systolic function in $\mathrm{db} / \mathrm{db}$ mice, although it reduces the degree of myocardial fibrosis and improves the LV relaxation constant in association with improved diastolic function, in addition to reducing myocardial p53 expression and apoptosis of cardiomyocytes.

\section{Clinical Investigation of Human Cardiac Function (Table)}

GLP-1 has been cited as improving myocardial function in T2DM patients with MI and/or HF. In patients with a low level of LV dysfunction after MI or PCI, infusion of GLP-1 results in an improvement of both the LVEF and wall motion. ${ }^{28,34} \mathrm{~A}$ randomized study assessing the effect of continuous GLP-1 infusion in 20 patients undergoing coronary artery bypass grafting documented improved glycemic control, reduced frequency of inotropic and vasoactive infusions, and a lower incidence of arrhythmias in the GLP-1-treated patients. ${ }^{35}$ Treatment with sitagliptin was found to improve dobutamine-induced regional wall motion abnormalities in ischemic segments on stress echocardiography and attenuate postischemic stunning in 14 patients with coronary artery disease (CAD) and preserved global LV function. ${ }^{36}$ Sokos et al demonstrated in a single-center nonrandomized trial that a continuous infusion of GLP-1 for 5 weeks in 12 patients with HF (New York Heart Association (NYHA) class III/IV) with or without T2DM improved the LVEF, oxygen consumption, 6-min walk test scores and quality of life, even in the nondiabetic patients. ${ }^{37}$ However, Halbirk et al reported that infusion of GLP-1 for $48 \mathrm{~h}$ in 15 nondiabetic patients with stable CHF (LVEF $<40 \%$ and NYHA class II-III) and HF reduced the blood glucose levels and increased the plasma insulin levels, although it had no significant effect on LV function, with only modest increases in HR and diastolic blood pressure (BP), in a double-blind placebo-controlled crossover design. ${ }^{38}$ Trainsdottir et al demonstrated a beneficial trend in cardiac function in patients with T2DM and HF after infusion of recombinant GLP-1. ${ }^{39}$ A short duration of infusion of GLP-1 may be insufficient to treat a decompensated failing heart.

\section{Other Possible Effects of Incretins on Cardiovascular Risk Factors}

\section{Lowering BP and Improving Endothelial Function}

In recent studies, DPP-4 inhibitors and GLP-1 analogs have been recognized as lowering systemic BP. ${ }^{40,41}$ A possible mechanism underlying this effect is the extraction of $\mathrm{Na}^{+}$, as GLP-1 induces natriuresis in humans. ${ }^{42}$

For diabetic vascular and endothelial injury, ${ }^{43}$ substantial data exist regarding the beneficial effects of GLP-1 and related drugs on endothelial function and the incidence of atherosclerosis, including (1) increasing the eNOS expression, ${ }^{44,45}$ (2) increasing the number of endothelial progenitor cells (EPCs) ${ }^{46}(3)$ decreasing the number of inflammatory cells and ROS production, ${ }^{47}$ and (4) reducing the adhesion and activation of macrophages, ${ }^{1,48}$ although these mechanisms cannot be described in detail in this review. Nevertheless, improved myocardial perfusion following the recovery of endothelial function may contribute to myocardial contractility. In addition, the incremental activity of eNOS may reduce BP, as increased BP is recognized by genetic deletion or pharmacological inhibition of NOS in vivo. ${ }^{49,50}$ Indeed, 


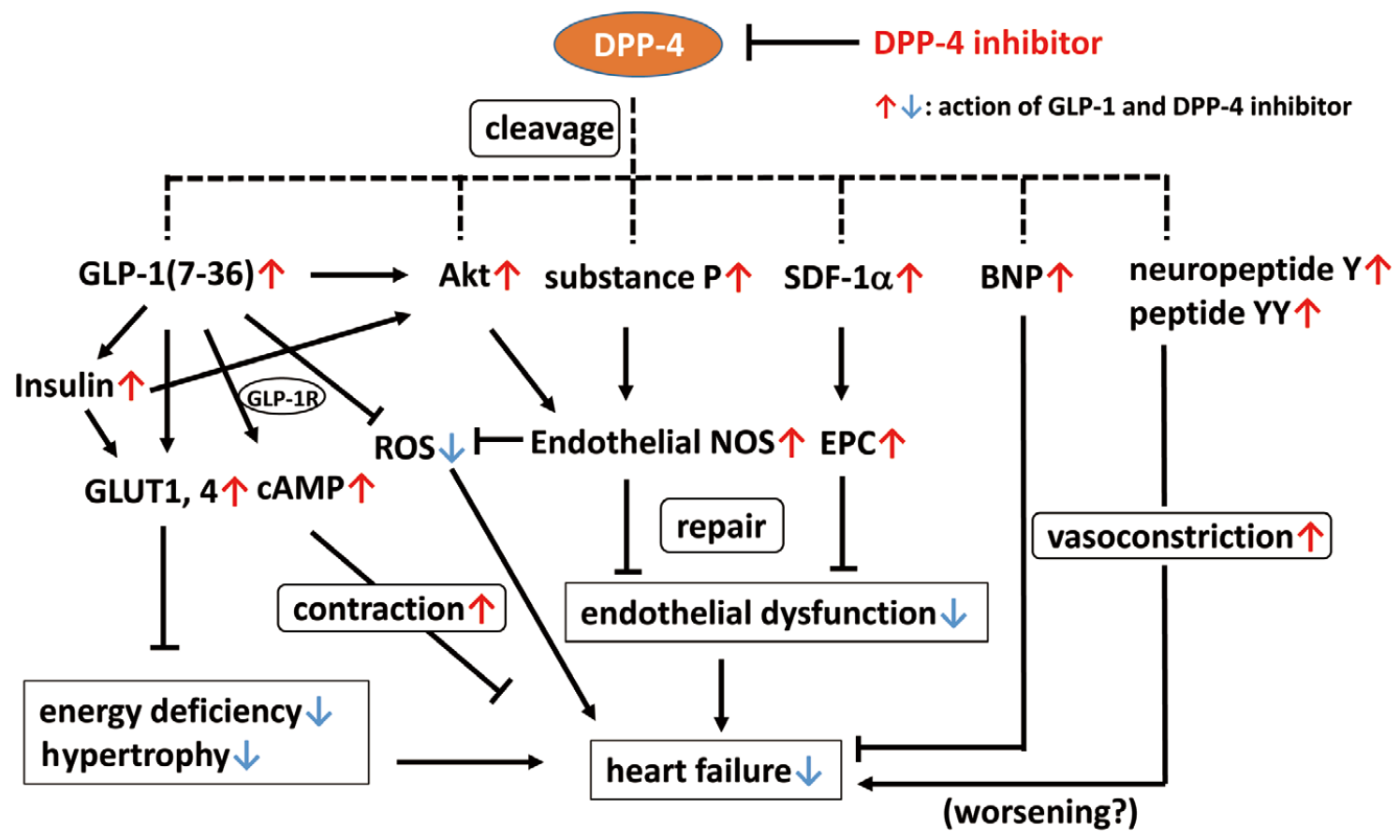

Figure 2. Possible mechanisms underlying the beneficial effects of incretins on the failing heart. In addition to the effects of GLP-1, DPP-4 cleaves a wide variety of substrates, DPP-4 inhibition keep the biological active forms of substrates and have many possible functions on cardiovascular system (red arrow). BNP, brain natriuretic peptide; DPP, dipeptidyl peptidase; EPC, endothelial progenitor cell; GLP-1, glucagon-like peptide-1; GLUT, glucose transporter; NOS, nitric oxide synthase; ROS, reactive oxygen species; SDF-1, stromal cell-derived factor-1.

sitagliptin improves endothelial function and reduces inflammation in patients with T2DM and CAD. ${ }^{51}$

\section{Shift of Cardiac Metabolism in the Failing Heart}

Alterations in myocardial substrate preference from FA to glucose are recognized in the failing heart. It may be substitutional. Therefore, insulin resistance with reduced GLUT-4 expression and increased levels of insulin are recognized in patients with HF. ${ }^{52}$ Although it is controversial whether myocardial glucose uptake is increased or not in the failing heart, DPP-4 inhibition or GLP-1 upregulate GLUT4 expression, and regulation of cardiac metabolism can be a therapeutic target for incretin therapy. ${ }^{53,54}$

\section{Possible Original Effects of DPP-4 Inhibitors}

In contrast to GLP-1 and GLP-1 receptor agonists, DPP-4 inhibitors inhibit DPP-4 throughout the body. As DPP-4 cleaves a wide variety of substrates, including stromal cell-derived factor-1 (SDF-1) alpha, which stimulates the bone marrow mobilization of EPCs and B-type natriuretic peptide (BNP) (1-32), the active form of BNP, ${ }^{55}$ DPP-4 inhibition repairs endothelial cells and improves cardiac function, thus resulting in an indirect improvement in endothelial function. Neuropeptide Y (NPY) and peptide YY (PYY) are also targets for cleavage by DPP-4. As both these peptides induce vasoconstriction through $\mathrm{Y}(1)$ receptors, inhibition of DPP-4 may result in vasoconstriction. ${ }^{56}$ Although it remains uncertain, NPY and its substrates appear to influence the cardiovascular system. These findings are promising, and the precise biological role of DPP-4 in the cardiovascular system requires further investigation. Figure 2 summa- rized the possible mechanisms underlying GLP-1 and DPP-4 inhibition in the failing heart.

\section{Incretins and Cardiovascular Outcomes}

\section{Do Incretins Really Improve Mortality From Cardiovascular Disease?}

Recently, the results of cardiovascular safety trials T2DM drugs (EXAMINE trial with alogliptin ${ }^{57}$ and SAVOR-TIMI 53 trial with saxagliptin ${ }^{58}$ ) were reported. These studies found no effect on the risk of fatal or nonfatal cardiac events and no increases in the risk of pancreatitis or pancreatic cancer. Although this is good news for users of these drugs, the results were disappointing because the studies did not demonstrate any cardiovascular protective benefits of DPP-4 inhibitors. On the other hand, the follow-up period was too short to evaluate the incidence of cardiovascular events, as the effects of drugs in combating proatherosclerotic processes in patients with diabetes mellitus usually requires more than 10 years. In the SAVOR-TIMI 53 trial, more patients were hospitalized for $\mathrm{HF}$ in the saxagliptin group than in the placebo group. These results are unexpected and should be considered within the context of multiple testing, which may have produced false-positive findings. The results of further subanalyses and other ongoing trials are waited. The relatively small $\mathrm{HbA}_{1 \mathrm{c}}$-lowering effects of saxagliptin and alogliptin observed in the SAVOR and EXAMINE trials, averaging only $0.3-0.4$ percentage points, must be also discussed. However, the effect of adequate glycemic control without severe hypoglycemia is irreplaceable for those with T2DM. Currently, new, safe tools are available for the treatment of T2DM. How- 
ever, new drugs require outrageous costs nowadays and both doctors and patients expect excessive benefits beyond conventional ones. Further studies must be conducted dispassionately as to whether incretin-related drugs have beneficial effects on prognosis, including the incidence of cardiovascular events, in humans.

\section{Conclusions}

Atherosclerosis and subsequent cardiovascular disease are often fatal, and providing early preventive care for cardiovascular complications by ensuring strict glucose control is essential for patients with T2DM. ${ }^{59}$ Although the final answer remains uncertain, the current findings add to a growing body of evidence suggesting that we may be entering a new era of cardiovascular diabetology with the development of new drugs. Ongoing randomized prospective clinical studies will provide more solid evidence regarding the long-term clinical effects of GLP-1-related therapies in patients with T2DM with a high risk of cardiovascular disease.

\section{Conflict of Interest Statement}

J.O. belongs to the endowed department by Fukuda Denshi Co, Ltd. K.N. received remuneration including lecture fees from AstraZeneca, Astellas Pharma Inc, Nippon Boehringer Ingelheim Co, Ltd, Pfizer Inc, MSD K.K., Daiichi Sankyo Company, Ltd, Kowa Pharmaceutical Co, Ltd, Takeda Pharmaceutical Co, Ltd, Novartis Pharmaceuticals Japan, Mitsubishi Tanabe Pharma Corporation, and Dainippon Sumitomo Pharma Co, Ltd. K.N also received scholarship funds or donations granted by Astellas Pharma Inc, Nippon Boehringer Ingelheim Co, Ltd, Daiichi Sankyo Company, Ltd, Takeda Pharmaceutical Co, Ltd, Mitsubishi Tanabe Pharma Corporation, and MSD K.K.

\section{References}

1. Arakawa M, Mita T, Azuma K, Ebato C, Goto H, Nomiyama T, et al. Inhibition of monocyte adhesion to endothelial cells and attenuation of atherosclerotic lesion by a glucagon-like peptide-1 receptor agonist, exendin-4. Diabetes 2010; 59: 1030-1037.

2. Nyström T, Gutniak MK, Zhang Q, Zhang F, Holst JJ, Ahrén B, et al. Effects of glucagon-like peptide-1 on endothelial function in type 2 diabetes patients with stable coronary artery disease. Am J Physiol Endocrinol Metab 2004; 287: E1209-E1215.

3. Ishibashi Y, Matsui T, Takeuchi M, Yamagishi S. Glucagon-like peptide-1 (GLP-1) inhibits advanced glycation end product (AGE)induced up-regulation of VCAM-1 mRNA levels in endothelial cells by suppressing AGE receptor (RAGE) expression. Biochem Biophys Res Commun 2010; 391: 1405-1408.

4. Ban K, Noyan-Ashraf MH, Hoefer J, Bolz SS, Drucker DJ, Husain M. Cardioprotective and vasodilatory actions of glucagon-like peptide 1 receptor are mediated through both glucagon-like peptide 1 receptordependent and -independent pathways. Circulation 2008; 117: 2340 2350.

5. Gallwitz B. Review of sitagliptin phosphate: A novel treatment for type 2 diabetes. Vasc Health Risk Manag 2007; 3: 203-210.

6. Vila Petroff MG, Egan JM, Wang X, Sollott SJ. Glucagon-like peptide-1 increases cAMP but fails to augment contraction in adult rat cardiac myocytes. Circ Res 2011; 89: 445-452.

7. Noyan-Ashraf MH, Momen MA, Ban K, Sadi AM, Zhou YQ, Riazi AM, et al. GLP-1R agonist liraglutide activates cytoprotective pathways and improves outcomes after experimental myocardial infarction in mice. Diabetes 2009; 58: $975-983$.

8. Gros R, You X, Baggio LL, Kabir MG, Sadi AM, Mungrue IN, et al. Cardiac function in mice lacking the glucagon-like peptide-1 receptor. Endocrinology 2003; 144: 2242-2252.

9. Dokken BB, La Bonte LR, Davis-Gorman G, Teachey MK, Seaver N, McDonagh PF. Glucagon-like peptide-1 (GLP-1), immediately prior to reperfusion, decreases neutrophil activation and reduces myocardial infarct size in rodents. Horm Metab Res 2011; 43: 300-305.

10. Dokken BB, Hilwig WR, Teachey MK, Panchal RA, Hubner K, Allen D, et al. Glucagon-like peptide-1 (GLP-1) attenuates post-resuscitation myocardial microcirculatory dysfunction. Resuscitation 2010; 81: $755-760$.

11. Zhao T, Parikh P, Bhashyam S, Bolukoglu H, Poornima I, Shen YT, et al. Direct effects of glucagon-like peptide-1 on myocardial contrac- tility and glucose uptake in normal and postischemic isolated rat hearts. J Pharmacol Exp Ther 2006; 317: 1106-1113.

12. Bhashyam S, Fields AV, Patterson B, Testani JM, Chen L, Shen YT, et al. Glucagon-like peptide-1 increases myocardial glucose uptake via p38alpha MAP kinase-mediated, nitric oxide-dependent mechanisms in conscious dogs with dilated cardiomyopathy. Circ Heart Fail 2010; 3: $512-521$

13. Bose AK, Mocanu MM, Carr RD, Brand CL, Yellon DM. Glucagonlike peptide 1 can directly protect the heart against ischemia/reperfusion injury. Diabetes 2005; 54: 146-151.

14. Matsubara M, Kanemoto S, Leshnower BG, Albone EF, Hinmon R, Plappert T, et al. Single dose GLP-1-Tf ameliorates myocardial ischemia/reperfusion injury. J Surg Res 2011; 165: 38-45.

15. Liu Q, Anderson C, Broyde A, Polizzi C, Fernandez R, Baron A, et al. Glucagon-like peptide-1 and the exenatide analogue AC3174 improve cardiac function, cardiac remodeling, and survival in rats with chronic heart failure. Cardiovasc Diabetol 2010; 9: 76.

16. Timmers L, Henriques JP, de Kleijn DP, Devries JH, Kemperman H, Steendijk P, et al. Exenatide reduces infarct size and improves cardiac function in a porcine model of ischemia and reperfusion injury. $\mathrm{J} \mathrm{Am}$ Coll Cardiol 2009; 53: 501-510.

17. Bao W, Aravindhan K, Alsaid H, Chendrimada T, Szapacs M, Citerone $\mathrm{DR}$, et al. Albiglutide, a long lasting glucagon-like peptide-1 analog, protects the rat heart against ischemia/reperfusion injury: Evidence for improving cardiac metabolic efficiency. PLoS One 2011; 6: e23570, doi:10.1371/journal.pone.0023570.

18. Sauve M, Ban K, Momen MA, Zhou YQ, Henkelman RM, Husain $\mathrm{M}$, et al. Genetic deletion or pharmacological inhibition of dipeptidyl peptidase-4 improves cardiovascular outcomes after myocardial infarction in mice. Diabetes 2010; 59: 1063-1073.

19. Zaruba MM, Zhu W, Soonpaa MH, Reuter S, Franz WM, Field LJ. Granulocyte colony-stimulating factor treatment plus dipeptidylpeptidase-IV inhibition augments myocardial regeneration in mice expressing cyclin D2 in adult cardiomyocytes. Eur Heart J 2012; 33: $129-137$.

20. Bose AK, Mocanu MM, Carr RD, Brand CL, Yellon DM. Glucagonlike peptide 1 can directly protect the heart against ischemia/reperfusion injury. Diabetes 2005; 54: 146-151.

21. Ku HC, Chen WP, Su MJ. DPP4 deficiency preserves cardiac function via GLP-1 signaling in rats subjected to myocardial ischemia/reperfusion. Naunyn Schmiedebergs Arch Pharmacol 2011; 384: 197-207.

22. Iwasa M, Yamada Y, Kobayashi H, Yasuda S, Kawamura I, Sumi S, et al. Both stimulation of GLP-1 receptors and inhibition of glycogenolysis additively contribute to a protective effect of oral miglitol against ischaemia-reperfusion injury in rabbits. Br J Pharmacol 2011; 164: $119-131$.

23. Bose AK, Mocanu MM, Carr RD, Yellon DM. Myocardial ischaemiareperfusion injury is attenuated by intact glucagon like peptide-1 (GLP-1) in the in vitro rat heart and may involve the p70s6K pathway. Cardiovasc Drugs Ther 2007; 21: 253-256.

24. Ye Y, Keyes KT, Zhang C, Perez-Polo JR, Lin Y, Birnbaum Y. The myocardial infarct size-limiting effect of sitagliptin is PKA-dependent, whereas the protective effect of pioglitazone is partially dependent on PKA. Am J Physiol Heart Circ Physiol 2010; 298: H1454-H1465.

25. Huisamen B, Genade S, Lochner A. Signalling pathways activated by glucagon-like peptide-1 (7-36) amide in the rat heart and their role in protection against ischaemia. Cardiovasc J Afr 2008; 19: 77-83.

26. Huisamen B, Genis A, Marais E, Lochner A. Pre-treatment with a DPP-4 inhibitor is infarct sparing in hearts from obese, pre-diabetic rats. Cardiovasc Drugs Ther 2011; 25: 13-20.

27. Hausenloy DJ, Yellon DM. New directions for protecting the heart against ischaemia-reperfusion injury: Targeting the Reperfusion Injury Salvage Kinase (RISK)-pathway. Cardiovasc Res 2004; 61: 448 460.

28. Nikolaidis LA, Elahi D, Hentosz T, Doverspike A, Huerbin R, Zourelias L, et al. Recombinant glucagon-like peptide-1 increases myocardial glucose uptake and improves left ventricular performance in conscious dogs with pacing induced dilated cardiomyopathy. Circulation 2004; 110: 955-961.

29. Nikolaidis LA, Elahi D, Shen YT, Shannon RP. Active metabolite of GLP-1 mediates myocardial glucose uptake and improves left ventricular performance in conscious dogs with dilated cardiomyopathy. Am J Physiol Heart Circ Physiol 2005; 298: H2401-H2408.

30. Poornima I, Brown SB, Bhashyam S, Parikh P, Bolukoglu H, Shannon RP. Chronic glucagon-like peptide-1 infusion sustains left ventricular systolic function and prolongs survival in the spontaneously hypertensive, heart failure-prone rat. Circ Heart Fail 2008; 1: 153-160.

31. Gomez N, Touihri K, Matheeussen V, Mendes Da Costa A, Mahmoudabady M, Mathieu M, et al. Dipeptidyl peptidase IV inhibition improves cardiorenal function in overpacing-induced heart fail- 
ure. Eur J Heart Fail 2012; 14: 14-21.

32. Yin M, Silljé HH, Meissner M, van Gilst WH, de Boer RA. Early and late effects of the DPP-4 inhibitor vildagliptin in a rat model of postmyocardial infarction heart failure. Cardiovasc Diabetol 2011; 10: 85 .

33. Lenski M, Kazakov A, Marx N, Böhm M, Laufs U. Effects of DPP-4 inhibition on cardiac metabolism and function in mice. $\mathrm{J} \mathrm{Mol} \mathrm{Cell}$ Cardiol 2011; 51: 906-918.

34. Lønborg J, Vejlstrup N, Kelbæk H, Bøtker HE, Kim WY, Mathiasen $\mathrm{AB}$, et al. Exenatide reduces reperfusion injury in patients with STsegment elevation myocardial infarction. Eur Heart J 2012; 33: 1491 1499.

35. Sokos GG, Bolukoglu H, German J, Hentosz T, Magovern GJ Jr, Maher TD, et al. Effect of glucagon-like peptide-1 (GLP-1) on glycemic control and left ventricular function in patients undergoing coronary artery bypass grafting. Am J Cardiol 2007; 100: 824-829.

36. Read PA, Khan FZ, Heck PM, Hoole SP, Dutka DP. DPP-4 inhibition by sitagliptin improves the myocardial response to dobutamine stress and mitigates stunning in a pilot study of patients with coronary artery disease. Circ Cardiovasc Imaging 2010; 3: 195-201.

37. Sokos GG, Nikolaidis LA, Mankad S, Elahi D, Shannon RP. Glucagonlike peptide-1 infusion improves left ventricular ejection fraction and functional status in patients with chronic heart failure. J Card Fail 2006; 12: 694-699.

38. Halbirk M, Nørrelund H, Møller N, Holst JJ, Schmitz O, Nielsen R, et al. Cardiovascular and metabolic effects of 48-h glucagon-like peptide-1 infusion in compensated chronic patients with heart failure. Am J Physiol Heart Circ Physiol 2010; 298: H1096-H1102.

39. Thrainsdottir I, Malmberg K, Olsson A, Gutniak M, Rydén L. Initial experience with GLP-1 treatment on metabolic control and myocardial function in patients with type 2 diabetes mellitus and heart failure. Diab Vasc Dis Res 2004; 1: 40-43.

40. Sakamoto Y, Oyama J, Ikeda H, Kuroki S, Gondo S, Iwamoto T, et al; S-DOG investigators. Effects of sitagliptin beyond glycemic control: Focus on quality of life. Cardiovasc Diabetol 2013; 12: 35.

41. Scheen AJ. Cardiovascular effects of gliptins. Nat Rev Cardiol 2013; 10: $73-84$

42. Gutzwiller JP, Tschopp S, Bock A, Zehnder CE, Huber AR, Kreyenbuehl M, et al. Glucagon-like peptide 1 induces natriuresis in healthy subjects and in insulin-resistant obese men. J Clin Endocrinol Metab 2004; 89: 3055-3061.

43. Gilbert RE. Endothelial loss and repair in the vascular complications of diabetes. Circ J 2013; 77: 849-856.

44. Ding L, Zhang J. Glucagon-like peptide-1 activates endothelial nitric oxide synthase in human umbilical vein endothelial cells. Acta Pharmacol Sin 2012; 33: 75-81.

45. Erdogdu O, Nathanson D, Sjöholm A, Nyström T, Zhang Q. Exendin-4 stimulates proliferation of human coronary artery endothelial cells through eNOS-, PKA- and PI3K/Akt-dependent pathways and requires GLP-1 receptor. Mol Cell Endocrinol 2010; 325: 26-35.

46. Xiao-Yun X, Zhao-Hui M, Ke C, Hong-Hui H, Yan-Hong X. Glucagon-like peptide-1 improves proliferation and differentiation of en- dothelial progenitor cells via upregulating VEGF generation. Med Sci Monit 2011; 17: BR35-BR41.

47. Shiraki A, Oyama J, Komoda H, Asaka M, Komatsu A, Sakuma M, et al. The glucagon-like peptide 1 analog liraglutide reduces TNF- $\alpha$ induced oxidative stress and inflammation in endothelial cells. Atherosclerosis 2012; 221: $375-382$.

48. Gaspari T, Liu H, Welungoda I, Hu Y, Widdop RE, Knudsen LB, et al. A GLP-1 receptor agonist liraglutide inhibits endothelial cell dysfunction and vascular adhesion molecule expression in an ApoE-/- mouse model. Diab Vasc Dis Res 2011; 8: 117-124.

49. Huang PL, Huang Z, Mashimo H, Block KD, Moskowitz MA, Bevan JA, et al. Hypertension in mice lacking the gene for endothelial nitric oxide synthase. Nature 1995; 377: 239-242.

50. Rees DD, Palmer RM, Moncada S. Role of endothelium-derived nitric oxide in the regulation of blood pressure. Proc Natl Acad Sci USA 1989; 86: $3375-3378$

51. Matsubara J, Sugiyama S, Akiyama E, Iwashita S, Kurokawa H, Ohba K, et al. Dipeptidyl peptidase-4 inhibitor, sitagliptin, improves endothelial dysfunction in association with its anti-inflammatory effects in patients with coronary artery disease and uncontrolled diabetes. Circ J 2013; 77: 1337-1344.

52. Stanley WC, Recchia FA, Lopaschuk GD. Myocardial substrate metabolism in the normal and failing heart. Physiol Rev 2005; 85: $1093-$ 1129.

53. Green CJ, Henriksen TI, Pedersen BK, Solomon TP. Glucagon like peptide-1-induced glucose metabolism in differentiated human muscle satellite cells is attenuated by hyperglycemia. PLoS One 2012; 7: e44284, doi:10.1371/journal.pone.0044284.

54. Giannocco G, Oliveira KC, Crajoinas RO, Venturini G, Salles TA, Fonseca-Alaniz MH, et al. Dipeptidyl peptidase IV inhibition upregulates GLUT4 translocation and expression in heart and skeletal muscle of spontaneously hypertensive rats. Eur J Pharmacol 2013; 698: $74-86$.

55. Vanderheyden M, Bartunek J, Goethals M, Verstreken S, Lambeir AM, De Meester I, et al. Dipeptidyl-peptidase IV and B-type natriuretic peptide. From bench to bedside. Clin Chem Lab Med 2009; 47: $248-252$.

56. Jackson EK, Zhang M, Liu W, Mi Z. Inhibition of renal dipeptidyl peptidase IV enhances peptide YY1-36-induced potentiation of angiotensin II-mediated renal vasoconstriction in spontaneously hypertensive rats. J Pharmacol Exp Ther 2007; 323: 431-437.

57. White WB, Cannon CP, Heller SR, Nissen SE, Bergenstal RM, Bakris GL, et al. Alogliptin after acute coronary syndrome in patients with type 2 diabetes. N Engl J Med 2013; 369: 1327-1335.

58. Scirica BM, Bhatt DL, Braunwald E, Steg PG, Davidson J, Hirshberg B, et al. Saxagliptin and cardiovascular outcomes in patients with type 2 diabetes mellitus. $N$ Engl J Med 2013; 369: 1317-1326.

59. Koshizaka M, Green JB, Alexander JH. Glycemic Management in Glycemic management in diabetes and the associated cardiovascular risk: Are we helping or hurting our patients? Circ J 2012; 76: 1572 1580 . 